\title{
15. THE DEVELOPING FIELD OF TECHNOLOGY EDUCATION IN NEW ZEALAND: THE LAST TWENTY YEARS
}

\section{INTRODUCTION}

In the last twenty years technology education in New Zealand has found a place in research, teacher education and classroom practice. This paper traces the development of technology education as a field of study in compulsory education over the last twenty years and explores the curriculum development in the 1990s, the emerging research field during that time as well as teacher pre and in-service development. Figure 1 outlines the key aspects of development of technology education in New Zealand and highlights key features of curriculum, research and teacher education and shows the links between these different aspects in a timeline from 1985 to 2005.

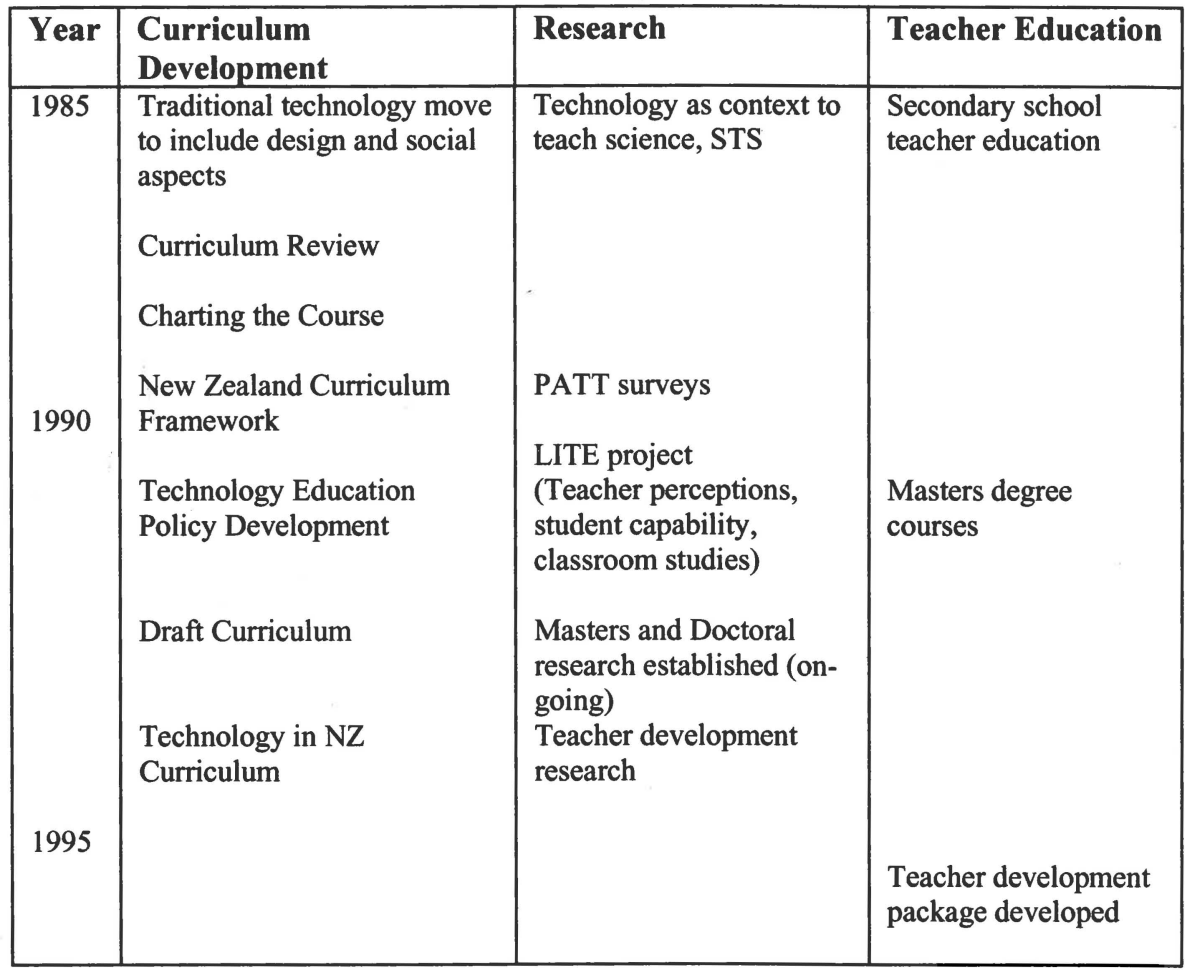




\begin{tabular}{|l|l|l|l|}
\hline 2000 & $\begin{array}{l}\text { Curriculum becomes } \\
\text { compulsory for years 1-10 } \\
\text { Development of national } \\
\text { qualifications }\end{array}$ & Research in assessment & $\begin{array}{l}\text { Large scale national } \\
\text { professional } \\
\text { development } \\
\text { Curriculum Stocktake } \\
\text { Primary School } \\
\text { teacher education } \\
\text { courses begin }\end{array}$ \\
& $\begin{array}{l}\text { Revised curriculum structure } \\
\text { Sampling Study } \\
\text { Classroom InSiTE } \\
\text { project }\end{array}$ & \\
& & & GIF funding for senior \\
& & & \\
\hline
\end{tabular}

Figure 1: Timeline of developments in technology in New Zealand

\section{DEVELOPMENT OF TECHNOLOGY FOR ALL IN THE CURRICULUM}

New Zealand has had a long history of technical education in the senior primary and secondary school (Burns, 1992). A national school system was introduced in New Zealand in 1877 and technical education was introduced in 1890 with metal and woodwork for boys and cooking, needlework and/or laundry for girls being taught in the last two years of primary schooling (10-12 years). At the same time technical high schools were developed and tended to channel working class children into manual and trade employment. After 1945 common core subjects such as metal and woodwork and cooking and sewing were introduced in all high schools for third and fourth form students (13-15 years).

During the 1980's there were moves to include more design foci and the use of a range of materials. This saw the emergence of such subjects as workshop technology and graphics and design. During this time there was also attempts to break down the gender stereotyping by having girls and boys taking all technical/technology subjects in senior primary and junior high school, however by the senior high school these subjects tended to be gender specific (McKenzie, 1992). Also during the 1980's there was an increasing emphasis of technology in existing school subjects such as science (technology as applied science), social studies (technological determinism) and information technology (computers). Technology therefore as it has developed in past curricula encompassed a limited 
range of skills, processes and knowledge resulting from a narrow and gender specific perspective. As a consequence students have not had the broad experiences in technology that they need to successfully contribute to society.

Technology as a separate subject area emerged in the 1990 curriculum reforms. These curriculum reforms were influenced by the curriculum reviews undertaken in the 1980s. In 1984, a review of the curriculum for schools was undertaken (Department of Education, 1987). The public discussion and consultation was substantial - 21,500 submissions initially, and 10,000 submissions to the draft report (from a total population of approximately 3.4 million at the time). It recommended that there be a national common curriculum for all schools, from new entrants to form 5 (years 1-10), that it includes national curriculum principles, and knowledge, skills, attitudes and values. In 1990, a new government embarked on a project to revise the curriculum in primary and secondary schools, under the banner of 'the Achievement Initiative' (Ministry of Education, 1991). Many of these ideas where influenced by the curriculum reforms taking place in England and Wales in the early 1990s. The policies emphasised raising standards; levels of attainment and the notion of progression linked to accountability; and the contracting out of the development process (Bell, Jones and Carr, 1995). As part of an educational review process a Ministerial Task Group Reviewing Science and Technology Education was set up jointly by the Minister of Education and the Minister of Research, Science and Technology, in June 1991, and which reported in 1992 (Ministry of Research, Science and Technology, 1992). Some of the recommendations from the task group concerning technology education, were that: a technology curriculum be developed as an area in its own right; there be adequate teacher training and resourcing for technology education; technology curricula should not be imported from overseas; the inclusiveness of technology education be emphasised including, Maori input and the use of Maori language ${ }^{1}$. This report was endorsed by members of the business community, and by two Ministers of the Crown. In 1992, the Ministry of Education contracted the Centre for Science and Technology Education Research, University of Waikato to develop a policy framework for technology education in New Zealand. The contract required that: there be wide consultation; best practice be taken into account, nationally and internationally; it be consistent with other Government policies in education; it to take account of resources, teacher change, teacher development, qualifications frameworks, etc; and where possible give a range of options. The development of the policy had to fit within the structure of the New Zealand Curriculum framework, in terms of levels, strands and achievement aims and objectives. The policy decided the general aims of the curriculum, the technological areas, classroom and implementation directions as well as approaches to assessment.

\footnotetext{
${ }^{1}$ Maori are the indigenous people of New Zealand and under the Treaty of Waitangi (1840) were guaranteed exclusive and undisturbed rights in terms of preservation of land, fisheries, forest and language. Maori has been an official language in New Zealand (along with English) since 1987.
} 
The general aims of technology education in Technology in the New Zealand Curriculum (Ministry of Education, 1995) were to develop:

- technological knowledge and understanding

- an understanding and awareness of the interrelationship between technology and society

- technological capability.

The three interrelated general aims provide a framework for developing expected learning outcomes, and make a valuable contribution to formulating a balanced curriculum for technology education. In the New Zealand technology curriculum the technological areas include: materials technology; information and communication technology; electronics and control technology; biotechnology; structures and mechanisms; process and production technology; and food technology. The individual objectives of the technology curriculum over 8 levels arise from the general aims of technology education.

The draft curriculum statement was trialed in schools during 1994. This provided teachers and others to respond to the draft statement. The responses generally indicated that teachers and professional technologists were supportive of the general structure and philosophy of the document. However, there was a need to reduce the number of objectives and strands given the number of other curriculum documents that teachers were dealing with. There was general consensus that the strands should reflect directly the three general aims of the technology curriculum: technological knowledge and understanding, technological capability and technology and society. The reduction in strands did in no way change the underlying philosophy but in fact strengthened the notion of technological practice as one of the conceptual bases of the curriculum. Other contexts were added and the number of learning experiences was reduced but an attempt was made to make these more holistic in nature. The final statement was released in October 1995. The curriculum was fully implemented by schools in February 1999. During the time between the release of the final statement in 1995 and implementation in 1999 teacher professional development programmes were been undertaken.

In 2001 a curriculum stocktake was undertaking with reviews of the curricula, international evaluations and teachers experiences of the curricula in practice. The current technology curriculum is currently being reviewed and it is proposed that the new organising strands of the technology curriculum be the nature of technology, technological knowledge and technological practice. The nature of technology strand focuses on students developing an understanding of the key characteristics of technology as a field of human endeavour. The technological knowledge strand focuses on students developing technological knowledge that underpins devices, systems/processes, and procedures. The technological practice strand focuses on supporting students undertaking technological practice and examining the practice of others. A programme developing student technological literacy provides experiences to develop understandings within each strand. This literacy is enhanced through exploring and understanding the inter-relationship of the strands. 


\section{CURRICULUM IN PRACTICE}

To develop an understanding of the curriculum in practice The National School Sampling Study (NSSS) provided an opportunity for teachers who had been involved in implementing technology in the New Zealand curriculum to share their experiences (Jones, Harlow, and Cowie, 2004). The primary purpose of the study was to seek feedback from teachers about the effectiveness of the curriculum in practice. The key aspects investigated included: background and experience of teachers, general issues related to implementation, practice, support, the curriculum documents, impact and compliance issues. The structure of the National School Sampling Study encompasses national focus groups, questionnaires and case studies. This section describes the results of a national study to investigate teachers' experiences in the implementation of the technology curriculum in New Zealand schools from years 1-13. This investigation of the implementation of the technology curriculum is part of a larger study being undertaken nationally in all curriculum areas (National Schools Sampling Study) to explore how effective the curriculum is in practice and how the results can inform future developments. National focus groups, questionnaires and case studies were used to explore how the curriculum is being implemented. The questionnaires were distributed to over $10 \%$ of New Zealand schools. There are about 2900 schools in New Zealand and 269 sent returns in late 2001.

Overall, the results provide a broad sweep of information about teachers' experiences, and the general impression is that most teachers are reasonably positive about teaching from the technology curriculum statement. However, there are variations between teachers in different kinds of schools and within school types, and especially between primary and secondary school teachers. In order to find out how useful teachers had found the technology curriculum statement the questions asked of teachers were framed around the structure of the statement, covering areas such as the structure of the curriculum, the support and professional development for technology teachers, assessment and reporting issues and strategies for curriculum implementation. There was a general degree of satisfaction with the curriculum statement in that only one third of teachers $(33 \%)$ wanted to make changes. The largest group who wanted to make changes to the structure/organization of the curriculum statement was senior secondary school (year 11-13) teachers (50\%). The most popular changes would be 'making it more simple to understand' and 'including more and better developed learning and assessment examples'. The technology curriculum statement has been of most help in planning, gaining an overview of the progression of key technological ideas, achieving consistent understanding of the curriculum levels and in assessing student achievement. Approximately half of all teachers sometimes found the curriculum statement helpful in gaining an overview of the progression of key ideas. 
Although $70 \%$ of teachers found the curriculum statement to be always or sometimes helpful in assessing achievement, many reported having difficulties with assessment in technology. The most popular way of assessing student learning in technology was the use of 'practical tasks'. Large classes, the 'time' factor, and establishing level accuracy, were also issues, but only noted by less than $20 \%$. Secondary school teachers were more concerned with the amount of paperwork required than teachers in other schools and were influenced by qualification requirements. At the primary level teachers were concerned about finding appropriate forms of assessment for the junior years and felt that they needed more guidance, both in planning and in assessment. More work needs to be undertaken in the area of assessment in technology.

With the introduction of the technology curriculum, an extensive programme of professional development was offered to teachers. In addition the Ministry of Education has published various resources to assist teachers in their implementation of the technology curriculum. Nearly three-quarters of the teachers (73\%) had received professional development in technology. 'Other teachers in the school' had been the most useful source of knowledge to almost $50 \%$ of teachers particularly secondary school teachers. For $75 \%$ of teachers professional development had been helpful and $28 \%$ had found it had given them a depth of knowledge and ideas so that they could plan and implement the technology curriculum. Professional development had helped many teachers to gain confidence in teaching technology. Across all school types two thirds of teachers expressed a medium level of confidence in teaching technology and one-fifth a high level of confidence. Teachers were most interested in receiving future professional development in the specific technological areas. Information on planning and teaching skills was requested and they were also interested in knowing more about progression, assessment and reporting achievement.

According to $88 \%$ of teachers, all students up to and including year 10 in their school studied technology. The majority of teachers considered that the technology curriculum should be compulsory for all students to the end of year 10, as it provided students with important skills. Over $60 \%$ of schools were integrating technology with other learning areas. This was particularly evident in primary schools $(71 \%)$, where teachers teach all curriculum areas. They tended to integrate technology into languages and science. Secondary school technology teachers taught technology in blocks or modules or as a new subject with its own timetable slots. Teachers detailed a wide range of approaches that had been successful in their teaching of technology. These included: choosing topics of relevance to students; practical, hands-on learning activities; a 'problem-solving approach'; and group or co-operative learning approaches. Teachers tended to favour a studentcentred approach to teaching technology.

Materials technology and food technology were reported to be the most widely taught technological areas in New Zealand schools. All other technological areas were being taught in schools, with biotechnology the least widely taught. Primary school teachers covered all the technological areas in their teaching. Fewer teachers in intermediate/middle schools taught electronics and control technology, 
and food technology perhaps because specialist technology teachers often covered these areas. At secondary school level, biotechnology seemed to be the least frequently covered. Overall it appears that apart from the traditional technological areas of food and materials technology, secondary school schools have not developed courses in other technological areas to the same extent as in primary schools.

The general impression was that technology was being implemented across all school types and at all levels. However, on looking more closely at the three main school systems, primary, intermediate and secondary school, it was clear that the challenges of the curriculum at each level were different. Teachers were asked to list the three major challenges they had faced in implementing the technology curriculum:

- The prime concern of teachers was the difficulty of resourcing the equipment needed to implement the technology curriculum (50\%);

- What was termed a 'crowded curriculum' was found to be a major challenge for $32 \%$ of all teachers, in particular the primary teachers;

- Teachers expressed the need for up-skilling or professional development in technology education (22\%);

- Understanding the curriculum was one of the major challenges for $22 \%$ of all teachers.

Primary school teachers reported a moderate level of confidence $(70 \%)$ in teaching technology and appeared to be well on the way to providing technological activities for their pupils in many of the technological areas. They asked for more support, in the form of practical ideas and nearly $60 \%$ of primary teachers said that a major challenge was the difficulty they had with resourcing and equipment. Their second major concern (32\%) was how to fit technology into an overcrowded curriculum. As teachers who teach all areas of the national curriculum, primary teachers reported overcoming this to a certain extent by integrating technology with other subject areas. Although many secondary school teachers have new facilities in which to work, they have had difficulties with establishing technology in their schools either because of timetable constraints, management decisions or lack of enthusiasm on the part of former home economics and wood/metal teachers. Fifty-three percent of secondary school grade 9-12 teachers placed more emphasis on technological capability than the other strands. Concerns about the level of student knowledge and skill to be able to cope with requirements of the curriculum were expressed by $31 \%$ of secondary school teachers. Biotechnology was the only technological area that secondary school schools did not cover so well. Secondary school teachers most often used products, practical tasks, observation and school exemplars in the assessment of technology.

The findings from the study offer interesting insights into how teachers have implemented this part of the New Zealand curriculum framework. There was a general degree of satisfaction with the curriculum statement that had been most helpful to teachers in their planning, gaining an overview of key technological ideas, and achieving consistent understanding of the curriculum levels. Teachers 
were using the curriculum statement to guide them in their assessment of student achievement, but primary teachers in particular expressed a need for more guidance. Secondary school teachers were grappling with the introduction of new national qualification requirements. Technology teachers have had to adapt more than in any other curriculum area to new ways of teaching. They have found the subject challenging yet have taken technology in their stride, and believe in the value of the subject for their students. The technology curriculum has clearly established itself in the culture of New Zealand schools. Assessment and progression are key issues for the future that were identified by the teachers in this study, this is consistent with research agendas in the field which point out that this is a significant area of study if the field of technology in schools is to progress (Jones and Moreland, 2003)

\section{TECHNOLOGY EDUCATION RESEARCH}

In the last twenty years research in New Zealand in technology education has increased significantly. In the 1980 's the research focused on using technology to enhance the learning of science e.g. using technological applications to teach science (Jones and Kirk, 1990). With a policy move in the late 1980's early 1990's to include a broad notion of technology in the curriculum, research was commissioned by the New Zealand Ministry of Education. This included research on student attitudes to technology based on the PATT questionnaires (Burns, 1992) and the Learning in Technology Education (LITE) research projects. The LITE projects (1992-1994) were carried out to inform both the curriculum and professional development in the implementation of the technology curriculum (Jones, Mather and Carr, 1995). The early LITE research focused on teachers' perceptions of technology and found the way in which teachers' existing subcultures influenced they way they might be prepared to implement the technology curriculum (Jones and Carr, 1992). The classroom investigations explored the way in which students carried out technological activities in the classroom. The classroom culture and student expectations appeared to strongly influence the way in which students carried out their technological activities (Jones, Mather and Carr, 1995). The final phase of the project explored effective characteristics of professional development for teachers in technology (Jones and Compton, 1998). This early research brought the focus onto the teacher and the learner. This time frame 1990-1995 also saw the emergence of Masters and $\mathrm{PhD}$ research in the area of technology education as the area developed prominence in both schools and tertiary education.

The focus of research from 1996-1998 was one teacher development as the full implementation of the curriculum loomed. However during this time there was no directly government-funded research as the resources were for professional development. However, some of the major professional development programmes built on teacher development research and some of the professional development programmes built in a research/evaluative component (for example Jones and Compton, 1998 and Compton and Jones, 1998). 
In 1998 there was a shift to focus much more on assessment, both formative and summative (Compton and Harwood, 2003, Moreland and Jones, 2000, Jones and Moreland, 2003). This focus moved the research much more back into the classroom. This focus resulted in moving the research area forward in four interrelated areas:

- Learning in technology for teachers

- Learning in technology for students

- Assessment in technology

- Progression in learning technology

A greater emphasis on researching teachers' teaching technology was undertaken. Teacher conceptualisation of technology and technology education is a complex issue and requires an understanding of the many factors that influence it. Some factors researchers noted as having a large impact on how willing teachers were to change their own concepts of technology and technology education included the perceived need for change, background experience, subject subculture, level of support given to teachers during any change process, and personal disposition towards dealing with implications of these changes (Jones, 1997). Classroom based research from 1992-1997 (Jones, 1999) showed that the strategies developed by the teachers in their classrooms when implementing technological activities were often positioned within that particular teacher's teaching and subject sub-culture. Teachers entering areas of uncertainty in their planned activities often reverted to their traditional teaching and subject sub-culture. For a new curriculum area such as technology, this presents particular challenges for teachers as they search to construct a coherent, technological content base and appropriate assessment practices (Moreland and Jones, 2000). Classroom observation and teacher interviews over seven years suggest that technological knowledge, an understanding of technological practice, and an appropriate conceptualisation of technology and technology education, are important in order to teach in the learning area of technology education. However, much more research is required in this area to understand and develop the appropriate teacher knowledges for teaching in the technology classroom.

Technology is an activity that involves not just the social context, but also the physical context, with thinking being associated with and structured by the objects and tools of action. This means research in student learning has to consider not just the conceptual and procedural understanding alone but also the way technological tools and objects influence and interact with student thinking and doing. Research began looking at student learning in classrooms began in 1993 but greater emphasis on researching students' learning in technology education, including ways in which this learning can be enhanced is required. This highlights the need for the identification of appropriate concepts and processes for school technology, students' existing knowledge of these and ways in which student learning in these might be enhanced. This requires much fuller investigation and is beginning as part of a longitudinal study to be undertaken over the next three years in primary school 
classrooms (Compton, 2004; Jones, Cowie and Moreland, 2004). In classroom technology there is a need for multi-dimensional data and for those using the information to study and understand its structure and its terminology. Assessment judgements become all the more difficult to make in a new subject area such as technology, where there is a lack of a shared subculture on the nature of the subject, insufficient accumulated practical classroom experience and a limited assessment structure. Assessment strategies in technology need to be research and developed along these lines highlighted above. Research in assessment in technology and teacher pedagogical content technology has become well established in last few years (for example Compton and Harwood, in press; Jones and Moreland, 2004)

Extensive classroom research between 1998-2000 by the research team from the Centre for Science and Technology Education Research, University of Waikato, led to a collection of a substantial data set (Moreland and Jones, 2000). This included: 700 hours of classroom observation; 1500 pieces of student work including student and teacher assessment; formal and informal student interviews; 100 formal teacher interviews; 400 informal teacher interviews; information from teacher workshops; and 50 lesson plans and lesson outlines. The data set contains work from students in Years 1 to 8 and from all technological areas with the work showing students undertaking technology tasks characteristic of everyday classroom technology. A reanalysis of a $3 \%$ national sample of student work from years 4 and 8 from the National Educational Monitoring Project in technology was also undertaken. This information may help to provide a model of progression in learning technology. Progression in learning in technology is reflected in the following categories:

- the nature of technology;

- dimensions of student technological practice;

- generic conceptual, procedural, societal and technical aspects and;

- specific conceptual, procedural, societal and technical aspects.

In comparing data between the year groups several trends are emerging. Compared with Year 4 students Year 8 students are more likely to consider a greater number and more functional alternatives; conflicting demands; and relationships between variables and the end user. They are more able to identify and operationalise a greater range of task variables. They demonstrate a greater use of technological language. Though hardly surprising, the trends assist us to understand what students can do and allow us to interact with students in more effective ways. Understanding capabilities students bring to tasks allows us to think about fast-forwarding particular aspects. Compton and Harwood (2004) showed that findings from research undertaken in 2001 research allowed for the identification of key features of components of practice. The three components of practice established were brief development, planning for practice, and outcome development and evaluation. 
In summary, the research in New Zealand has shown that to enhance and sustain learning in technology there needs to be a focus on teacher knowledge of specific and detailed technological learning outcomes in conjunction with appropriate pedagogical approaches. Of particular importance was the use of a well-developed framework to focus the teachers' attention on the conceptual, procedural, societal and technical aspects of student learning in technology. However this is only the beginning and much more work over a sustained period needs to be developed. Although this research has a positive impact in the classroom much more research needs to be carried out on the development of models of progression and ways to enhance interactions with students in technology. If we are to move technology education forward as a significant area of learning for all students then there needs to be a much stronger focus on research in classrooms rather than the previous research effort.

\section{PRE AND IN-SERVICE TEACHER EDUCATION}

As teacher education institutions began to grapple with the introduction of technology education courses into teacher programmes the Ministry of Education was undertaking national professional development programmes. For the implementation of technology the Ministry of Education provided approximately \$NZ22 million for professional development purposes. These national programmes had been informed by two teacher professional development programmes developed under contract from the Ministry of Education by the Centre for Science and Technology Education Research (1995-1997). These initial programmes were the National Facilitator Training Programme, and the Technology Teacher Development Resource Package (For full details of these programmes and the evaluation see Jones and Compton, 1998 and Compton and Jones, 1988). These teacher development programmes took into account past national and international research in teacher development, as well as recent technology education baseline research carried out in New Zealand schools (Jones, Mather and Carr, 1995).

Technology Education forms a part of all pre-service education for all primary school teachers. It is compulsory since technology is an essential learning area of the New Zealand Curriculum Framework with most institutions teaching technology education after it was fully implemented in 1999. However there are differences in emphasis depending on the structure of the institution. Teacher education takes a variety of forms within the Colleges of Education and Universities and there are a number of pathways. The Bachelor of Teaching is a three-year degree that prepares students for teaching in primary, intermediate or middle schools. This programme can be delivered at a distance through web-based media from a number of institutions. The first graduates educated in this way from this media graduated in 2000. The Graduate Diploma of Teaching (Primary) is a one-year programme for University graduates wishing to teach primary, intermediate or middle school students. For secondary school teacher education there are currently two pathways. There is the one-year Graduate Diploma of Teaching (Secondary) programme for graduates to teach in areas of their initial 
degree specialization, and the Bachelor of Teaching (Secondary), which is a conjoint degree programme. In this last programme the student studies for a degree in a relevant disciple as well as study in the teacher education programme. There are also Bachelor of Teaching (Honours) programmes that allow for students to gain greater depth and specialisation in various aspects of teaching.

The general structure of a primary teacher education course in technology is firstly to explore concepts of technology and technology education. In the course material the students are introduced to a number of different design concepts as well as the history of design and technology. The societal and values aspects of technology are highlighted for the students. There is an emphasis on design and the process of undertaking a technological project to develop an understanding both of technology and also to become aware of issues that children in schools might have to deal with as they learn technology. Through engagement in technology students are also made aware of issues that they may face in the classroom in terms of ways to teach technology, such as problem solving, group work, and resources. Early in the courses students are introduced to undertaking their own technological projects. In the short time that is available for the compulsory curriculum areas the emphasis in the courses has been to develop students understanding of the nature of technology and then make them aware of the characteristics of different technological areas. Although there are seven technological areas because of the limited time available the areas of Structures and Mechanisms and Materials are usually highlighted. These are also the most commonly taught areas in primary schools. The students are introduced to technical aspects, such as health and safety, drawing and construction techniques. Students are introduced to the curriculum in terms of its philosophy, strands, achievement objectives and examples of unit plans developed by other teachers to show the link between the curriculum and ways of planning. There is significant emphasis on planning for technology in the classroom. Thinking about scenarios through to curriculum objectives and then to specific learning outcomes. During this time the students are also introduced to ways of managing technology in the primary classroom. Assessment is another significant area that is introduced to the students, particularly in terms of both formative and summative assessment.

The graduate course development has been a significant one since the majority of teachers who are currently teaching technology trained without any formal technology education courses. The first course in technology education at the graduate level started in 1993 at the University of Waikato. With the release of the draft Technology in the New Zealand Curriculum in late 1993 there were a larger number of teachers studying the course in 1994. The structure of these courses will be discussed in comparison with those at the undergraduate level. Since 1995 one other university has developed a masters technology education programme and a College of Education developed a Technology education masters course at the later date. Two Universities (Massey University and The University of Waikato) developed master's programmes in technology education. From the initial face to face classes taught during semester time technology education now has been taught in distance mode, summer school and more recently there has been the 
development of fully web-based courses that are asynchronous and can be delivered internationally. As well as developing courses in technology education, that is courses with content related to the nature of technology, learning in technology, technology curriculum and issues such as teacher development and assessment, other courses were developed which emphasised the content area of technology such as technological knowledge, technological innovation, technology and society etc. At this graduate level the courses have traditionally been designed to assist practicing teachers develop knowledge to teach technology in the classroom.

In technology education graduate courses there is considerable emphasis on the nature of technology and technology education. This part of the course examines the history and philosophy of technology, the nature of technological knowledge, technological development in society etc. The courses then tend to examine learning theories associated with learning in technology and in particular current research in learning in technology such as technological problem solving, approaches to design, student conceptual understanding etc. An analysis of technology curriculum internationally and nationally is usually undertaken as well as a study of the historical development of the area of technology education. The graduate courses in technology education also consider such issues as professional development, gender and ethnicity, assessment, etc. The other graduate content area courses in technology are much more wider in range and are aligned to the expertise of the provider. These courses are design to develop the content areas associated with technology such as technology innovation and development, designing, manufacture, electronics, food technology. These courses are often taught by staff from the technology or engineering departments in the Universities.

\section{CONCLUSION}

This paper has attempted to briefly outline the development of technology education as a field of endeavour over the last 20 years. In twenty years technology education has moved from a subject limited to technical skills for a few students to a subject concerned with technological literacy for all students. Technology Education has become established in the rhetoric and practice of the classroom from year 1-13. However there is a range of both practice and time spent on technology education in the classroom (Jones, Harlow and Cowie, 2004). Technology is being squeezed in a curriculum that is being influenced strongly by literacy and numeracy initiatives in the primary school and new qualifications in the secondary school. Research on teachers introducing technology in their classrooms would show that these teachers had very high levels of pedagogical knowledge and were highly effective practitioners (Jones and Moreland, 2004). It has also been shown that these teachers can become highly effective technology teachers with appropriate teacher professional development. Overall, technology is becoming part of the school curriculum and teacher education at the pre-service level is beginning to contribute to this. The curriculum is currently under-going some changes to better reflect our understanding of both technology and learning 
in technology. There will be greater emphasis placed on the nature of technology and technological knowledge. Although these aspects are in the existing curriculum greater attention will be drawn to them.

In terms of research we have seen not only a greater amount of research but also a shift from defining the subject, teachers and student perceptions, through to professional development of teachers and now a much greater focus on learners and learning. This evident in an increase in classroom based research, including assessment and progression. Although there has been research carried out by research teams there has been an associated increase in graduate research being undertaken nationally. Technology education research and practice has emerged as being a significant area of the curriculum but still has someway to go to be seen in the same light as other well-established subjects such as science and social studies.

Although it may appear from Figure 1 that curriculum development, research and teacher education have in some ways proceeded separately there have been direct links between these three aspects. The policy work for technology education was informed by extensive international literature reviews and also the original Learning in Technology Education Research project. The literature searches highlighted the nature of technology and technology education as well as issues related to curriculum development in other countries. New Zealand was fortunate in this regard to build on the experiences of others. The research examined teacher and student perceptions and conducted classroom studies of student technological problem solving. The research also informed issues such as implementation strategies, that is, taking into account teacher subcultures, student perceptions and teacher development priorities. The teacher development strategies were also informed by the early research and formed the basis of the development of national facilitator training and teacher development packages. The evaluation of these programmes as well as the LITE research informed the development courses for pre service and as well courses at the graduate level. The Curriculum Stocktake was informed by the National School Sampling Study and this contributed to a number of initiatives such as revisions to the curriculum, increased initiatives such as Growth and Innovation Fund money for the senior secondary school as well increased research and development in the area of biotechnology. The research in assessment has influenced teacher education programmes as well as on-going resource development. Recent classroom research (from 2000) is informing the current revisions of the technology curriculum statement, particularly in terms of the nature of technology and technological knowledge.

In conclusion, technology education has become part of the curriculum for all students in New Zealand and is a compulsory component of primary pre-service teacher education. National school qualifications have been developed and pathways to tertiary education are becoming established. Technology education in schools continues to compete for space with other curriculum areas. The research field continues to grow with increased number of researchers, both individually and in larger teams. 


\section{REFERENCES}

Bell, B., Jones A., and Carr, M. (1995) The development of the recent national New Zealand science curriculum. Studies in Science Education 26, 73-105

Burns, J., (1992) Technology - What is it, and what do our students think of it? The NZ Principal, 6 (3), $22-25$.

Compton, V.J. (2004) So - What is technological knowledge? Developing a framework for technology education in New Zealand. 3rd biennial international conference on technology education research. 9-11 December 2004, Queensland, Australia.

Compton, V., and Jones, A., (1998) Reflecting on teacher development in technology education: Implications for future programmes. International Journal of Technology and Design Education. $8,2,151-166$

Compton, V. and Harwood, C. (2003) Enhancing technological practice: An assessment framework for technology education in New Zealand. International Journal of Design and Technology Education Vol 13, \#1, 1-26.

Compton, V.J. and Harwood, C.D. (In Press) Progression in technology education in New Zealand: components of practice as a way forward. Paper accepted for publication in International Journal of Design and Technology Education

Department of Education, (1987) The curriculum review. Report of the committee to review the curriculum for schools. Wellington: Government Printer.

Jones, A., (1997) Recent research in student learning of technological concepts and processes. International Journal of technology and design education Vol 7, No. 1-2 p 83-96.

Jones A (1999) The influence of teachers' Subcultures on curriculum innovation. In Loughran J, Researching Teaching. London, Falmer Press

Jones, A., and Carr, M., (1992) Teachers' perceptions of technology education - implications for curriculum innovation. Research in Science Education, 22 230-239

Jones, A., and Compton, V., (1998) Towards a model for teacher development in technology education: from research to practice. International Journal of Technology and Design Education. Vol 8, 1, 51-65.

Jones, A Harlow A and Cowie B (2004) New Zealand teachers' experiences in implementing the technology curriculum International Journal of Technology and Design Education, 14, 101-119

Jones A. and Kirk C. (1990). Introducing technological applications into the physics classroom. Help or hindrance to learning? International Journal of Science Education. 12, 5, 481-490.

Jones A and Moreland J (2003) Developing classroom-focused research in technology education. Canadian Journal of Science, Mathematics and Technology Education 51-66.

Jones, A., Mather V., and Carr, M., (1995) Issues in the practice of technology education. Vol 3: Centre for Science and Mathematics Education Research, University of Waikato.

McKenzie, D., (1992) The technical curriculum: Second class knowledge, In McCulloch G., (Ed) The school curriculum in New Zealand: History, theory, policy and practice. Palmerston North: Dunmore Press.

Ministry of Education, (1991) The achievement initiative. Education Gazette, 70 (7), 1-2, 16 April.

Ministry of Education, (1995) Technology in the New Zealand curriculum. Wellington: Learning Media

Ministry of Research, Science and Technology (1992) Charting the course: The report of the ministerial task group into science and technology education. Wellington: Government Printer.

Moreland, J and Jones, A. (2000) Emerging assessment practices in an emergent curriculum: Implications for technology. International Journal of Technology and Design Education. 10: 283-305. 